\title{
Development and Validation of a Risk Score to Predict the Frequent use of Emergency House Calls among Older People who Receive Regular Home Visits
}

\author{
Yu Sun \\ University of Tsukuba \\ Masao Iwagami ( $\nabla$ iwagami-tky@umin.ac.jp ) \\ University of Tsukuba \\ Nobuo Sakata \\ University of Tsukuba \\ Tomoko Ito \\ University of Tsukuba \\ Ryota Inokuchi \\ University of Tsukuba \\ Kazuaki Uda \\ University of Tsukuba \\ Shota Hamada \\ University of Tsukuba \\ Miho Ishimaru \\ University of Tsukuba \\ Jun Komiyama \\ University of Tsukuba \\ Naoaki Kuroda \\ University of Tsukuba \\ Satoru Yoshie \\ University of Tokyo \\ Tatsuro Ishizaki \\ Tokyo Metropolitan Institute of Gerontology \\ Katsuya lijima \\ University of Tokyo \\ Nanako Tamiya \\ University of Tsukuba
}




\section{Research Article}

Keywords: home health care services, risk score, emergency house calls, high-risk patients

Posted Date: December 16th, 2021

DOI: https://doi.org/10.21203/rs.3.rs-1147511/v1

License: (c) (i) This work is licensed under a Creative Commons Attribution 4.0 International License. Read Full License 


\section{Abstract}

Background: Demand for home care services is increasing in Japan, and a 24-hour on-call system could be a burden for primary care physicians. Identifying high-risk patients who need frequent emergency house calls could help physicians prepare and allocate medical resources. The aim of the present study was to develop a risk score to predict the frequent use of emergency house calls in patients who receive regular home visits.

Methods: We conducted a retrospective cohort study with linked medical and long-term care claims data from two Japanese cities. Participants were $\geq 65$ years of age and had newly started regular home visits between July 2014 and March 2018 in Tsukuba city and between July 2012 and March 2017 in Kashiwa city. A total of 4,888 eligible patients were randomly divided into a derivation cohort $(n=3,259)$ and a validation cohort $(n=1,629)$. The primary outcome was the frequent use of emergency house calls, defined as the use once per month or more on average during each observation period. We considered pre-specified variables, such as age, gender, medical procedure performed in home health care, long-term care need level, and medical diagnosis at the start of the regular home visit. We used the least absolute shrinkage and selection operator (Lasso) method to select predictor variables.

Results: The frequent use of emergency house calls was observed in $13.0 \%$ participants $(424 / 3,259)$ in the derivation cohort and $12.9 \%$ participants $(210 / 1,629)$ in the validation cohort. The risk score included three variables with the following point assignments: home oxygen therapy (4 points); care need level 4-5 (2 point); cancer (5 point). The area under the curve (AUC) in the derivation cohort was 0.708 , whereas the AUC of a model that included all pre-specified variables was 0.729 . The AUC in the derivation cohort was 0.708 , showing moderate discrimination.

Conclusions: This easy-to-use risk score would be useful for assessing high-risk patients and would allow the burden on primary care physicians to be reduced through measures such as clustering high-risk patients in well-equipped medical facilities.

\section{Introduction}

In recent years, the organization of primary health care after office hours has changed in many countries. There are new models for after-hours care, such as large-scale general practice cooperatives, primary care centers integrated into hospital emergency departments, or telephone triage and consultation services [1]. These changes are partly due to primary care physicians' reluctance to commit to being on-call 24-hour a day and 7 days a week because of the workload burden, increasing patient demand for after-hours care, and regional shortages of primary care physicians $[2,3]$.

In Japan, where the population is aging the fastest in the world [4], the demand for home care services has also increased due to the aging population and the government-sponsored shift of care from the hospital to the community [5]. However, previous research has shown that more than $70 \%$ of physicians in home care support clinics (HCSCs) feel burdened by the 24-hour on-call coverage mandated for HCSCs 
[6]. To enhance home medical care, it is essential to identify a high-risk population who frequently use emergency house calls and take measures to reduce physical and psychological burdens for primary care physicians.

Studies have shown that the common reasons for emergency house calls are fever, end-of-life care, dyspnea, and cough among patients who receive regular home visits in Japan [7, 8]. However, these studies focused on the chief complaint and did not consider factors of the patient's condition such as comorbidities or medical procedures performed in the home care setting. In addition, they were single- or few-center studies, which limits their generalizability. To take measures to relieve the burden on primary care physicians, it is necessary to assess the risk of patients who frequently use emergency house calls. However, to date, no study has developed risk prediction models for the frequent use of emergency house calls.

Using claims data from two Japanese cities, we developed and validated a risk score that includes comorbidities and medical interventions in home health care to predict the frequent use of emergency house calls among older people who receive regular home visits.

\section{Methods}

\section{Data source}

We obtained linked data on medical and long-term care insurance claims from the municipal governments of two cities (Tsukuba city, Ibaraki Prefecture, and Kashiwa city, Chiba Prefecture) in Japan. The populations of Tsukuba city and Kashiwa city in 2015 were approximately 224,000 and 410,000, respectively, with about $43,000(19.2 \%)$ and 97,000 (23.7\%) people $\geq 65$ years. For this research, the data were available from April 2014 to March 2019 in Tsukuba city and from April 2012 to March 2018 in Kashiwa city. As both cities are suburbs in the Tokyo metropolitan area and there are no major differences in the characteristics of the two cities, we combined their data to increase the generalizability of study findings.

Medical claims data included data from individuals with National Health Insurance for the self-employed and retirees under 75 years and Late-stage medical care system for the elderly for individual prefectures, while data from individuals with other health insurance credentials (e.g., insurance for corporate employees) were not included [9]. Medical insurance claims records included covered diagnoses, medical procedure information, and prescription information on a monthly basis. The recorded diagnoses were based on the original Japanese disease codes linked to the International Classification of Diseases 10th Revision (ICD-10) codes [10].

Under the statutory long-term care insurance system, older people who need living assistance can receive care services based on the seven levels of the certificate of need for long-term care: Support 1 (lowest disability) to 2 and Care 1 to 5 (highest disability) [11]. All Japanese citizens who are $\geq 65$ and individuals 40-64 years whose need of care is derived from aging-related diseases, such as stroke, cancer, and 
rheumatoid arthritis, are eligible for benefits. Long-term care need level is a nationally standardized certification that is assessed based on a person's physical and cognitive functioning [12]. Long-term care insurance claims data contains information on the care need levels and services used for all residents receiving long-term care services.

The linkage between medical and long-term claims data was made in each municipal government using personally identifiable information. In the data we received, anonymized ID numbers were assigned to individuals in both medical and long-term care insurance claim datasets.

\section{Study design and population}

We conducted a retrospective cohort study. Individuals who had newly started availing regular home visits between July 2014 and March 2018 in Tsukuba city and between July 2012 and March 2017 in Kashiwa city were included $(n=5,895)$. Individuals who did not receive regular home visits between April and June 2014 in Tsukuba city and between April and June 2012 in Kashiwa city were considered newly enrolled. First, we excluded people whose medical and long-term care claims data could not be linked $(\mathrm{n}=$ 534). Next, we excluded people who were $<65$ years when they started regular home visits $(n=242)$. The age of 65 years was chosen as the lower limit because (i) all people $\geq 65$ years are eligible for long-term care insurance benefits, (ii) the vast majority (over 95\%) of regular home visits are conducted for this age group [13]. We then excluded those who had a certificate of support level 1 or $2(n=231)$, because home visits are generally performed for patients who are disabled and cannot go to a clinic or hospital. Thus, a final sample of 4,888 individuals was evaluated (Figure 1).

\section{Outcome variable}

The primary outcome of the present study was the frequent use of emergency house calls during the period of regular home visits. The frequent use of home emergency calls was defined as the use on average once per month or more during each observation period. We followed patients to one year after the start of the regular home visit or until the month following the end of the regular home visit if it was completed within one year. During the period, the total number of emergency house calls was determined using medical insurance records. We calculated the average number of emergency house calls per month by dividing the total number of emergency house calls by the number of months each person received regular home visits (1-13 months).

\section{Predictor variable}

For each patient, we pre-defined variables potentially associated with the frequent use of emergency house calls, including age (categorized as $65-74,75-84,85-94$, or $\geq 95$ years); gender; medical procedures performed in home health care including self-injection, central venous nutrition, enteral nutrition, home oxygen therapy [7], use of ventilator/tracheostomy performed, and urinary selfcatheterization; long-term care need levels [7] classified as care need level 1-3, and care need level 4-5; medical diagnosis at the start of the regular home visit, including cerebrovascular diseases, cardiac diseases, lower respiratory tract diseases, joint diseases, dementia, Parkinson's disease, diabetes, visual 
of hearing impairment, fractures, and cancer. Medical interventions performed in the month in which the regular home visit began were identified from medical insurance claims records. In contrast, the care need levels were determined at the time of the most recent use of long-term care insurance service within three months of the start of the regular home visit. We identified medical diagnoses from medical insurance claims data during the three months before the start of the regular home visit. Medical diagnoses were categorized based on ICD-10 codes related to diseases associated with the initiation of long-term care in the Comprehensive Survey of Living Conditions in Japan [14] (Supplementary Appendix 1). The "suspected" diagnosis codes were excluded from the datasets.

\section{Statistical analysis}

Two-thirds of the study participants $(n=3,259)$ were randomly assigned to a derivation cohort to develop risk prediction models using computer-generated random numbers. The remaining third $(n=1,629)$ was reserved as an internal validation cohort. Among the patients assigned to the derivation cohort, we compared those with frequent use of emergency house calls and the others by using chi-square tests or Fisher's exact test when the expected frequency was less than 5. Then we performed multivariable logistic regression analysis with all pre-specified variables included. To create the most efficient and easyto-use risk score in actual clinical practice, we used Lasso logistic regression to select predictor variables. Lasso is an extended standard regression model, developed as a parsimonious prediction model by selecting important predictors [15]. The model resulting from Lasso is known to have better predictive model selection performance and predictor identification than classical regression methods [16]. We extracted the variables through Lasso logistic regression to build the predictive model by 5 -fold crossvalidation with the largest lambda at which the mean-squared error (MSE) was within one standard error of the minimal MSE [17]. Using the variables selected with Lasso, we derived a scoring system by multiplying each beta coefficient by four and rounding to the nearest integer [18]. The integer values of all applicable variables were then summed to determine a total score for each patient. The Receiver Operating Characteristic (ROC) curve for the risk score was drawn, and the area under the curve (AUC) was compared with the model in which all previously specified variables were included. To test the performance of our risk scores, we assessed discrimination by measuring the AUC from the validation cohort. Calibration was assessed graphically by plotting the average predicted probabilities against the observed probabilities corresponding to the quintiles of predicted probabilities.

All analyses were conducted using STATA version 15 (Stata Corp., Texas, USA). Statistical significance was set at $P<0.05$.

\section{Results}

We included 3259 people in the derivation cohort and 1629 in the validation cohort. Clinical characteristics are summarized in Table 1. 
Table 1

Characteristics of patients in the derivation cohort and the validation cohort.

\begin{tabular}{|c|c|c|c|}
\hline & $\begin{array}{l}\text { Entire } \\
\text { cohort }\end{array}$ & $\begin{array}{l}\text { Derivation } \\
\text { cohort }\end{array}$ & $\begin{array}{l}\text { Validation } \\
\text { cohort }\end{array}$ \\
\hline & $N=4,888$ & $N=3,259$ & $N=1,629$ \\
\hline & n (\%) & $\mathrm{n}(\%)$ & $\mathrm{n}(\%)$ \\
\hline Mean age, years (SD) & $84.1(7.4)$ & $84.0(7.5)$ & $84.3(7.3)$ \\
\hline \multicolumn{4}{|l|}{ Age category (years) } \\
\hline $65-74$ & $505(10.3)$ & $353(10.8)$ & $152(9.3)$ \\
\hline $75-84$ & $\begin{array}{l}1895 \\
(38.8)\end{array}$ & $1260(38.7)$ & $635(39.0)$ \\
\hline $85-94$ & $\begin{array}{l}2131 \\
(43.6)\end{array}$ & $1402(43.0)$ & $729(44.8)$ \\
\hline$\geq 95$ & $357(7.3)$ & $244(7.5)$ & $113(6.9)$ \\
\hline Gender: male & $\begin{array}{l}1972 \\
(40.3)\end{array}$ & $1317(40.4)$ & $655(40.2)$ \\
\hline \multicolumn{4}{|l|}{ Medical procedure at home } \\
\hline Self-injection & $99(2.0)$ & $73(2.2)$ & $26(1.6)$ \\
\hline Central venous nutrition & $64(1.3)$ & $45(1.4)$ & $19(1.2)$ \\
\hline Enteral nutrition & $14(0.3)$ & $12(0.4)$ & $2(0.1)$ \\
\hline Home oxygen therapy & $292(6.0)$ & $199(6.1)$ & $93(5.7)$ \\
\hline Use of ventilator/ tracheostomy performed & $30(0.6)$ & $24(0.7)$ & $6(0.4)$ \\
\hline Urinary self- catheterization & $18(0.4)$ & $13(0.4)$ & $5(0.3)$ \\
\hline \multicolumn{4}{|l|}{ Long-term care need levels } \\
\hline Care-need levels 1-3 & $\begin{array}{l}3019 \\
(61.8)\end{array}$ & $2007(61.6)$ & $1012(62.1)$ \\
\hline Care-need levels 4-5 & $\begin{array}{l}1869 \\
(38.2)\end{array}$ & $1252(38.4)$ & $617(37.9)$ \\
\hline $\begin{array}{l}\text { Medical diagnosis at the start of the regula } \\
\text { visit }\end{array}$ & & & \\
\hline
\end{tabular}

Abbreviations: SD = Standard Deviation, IQR = Inter Quartile Range.

*Emergency house calls once per month or more on average during each observation period. 


\begin{tabular}{|c|c|c|c|}
\hline & $\begin{array}{l}\text { Entire } \\
\text { cohort }\end{array}$ & $\begin{array}{l}\text { Derivation } \\
\text { cohort }\end{array}$ & $\begin{array}{l}\text { Validation } \\
\text { cohort }\end{array}$ \\
\hline & $N=4,888$ & $N=3,259$ & $N=1,629$ \\
\hline & $\mathrm{n}(\%)$ & $\mathrm{n}(\%)$ & $\mathrm{n}(\%)$ \\
\hline Cerebrovascular diseases & $\begin{array}{l}1953 \\
(40.0)\end{array}$ & $1277(39.2)$ & $676(41.5)$ \\
\hline Cardiac disease & $\begin{array}{l}2783 \\
(56.9)\end{array}$ & $1863(57.2)$ & $920(56.5)$ \\
\hline Lower respiratory tract disease & $\begin{array}{l}2240 \\
(45.8)\end{array}$ & $1478(45.4)$ & $762(46.8)$ \\
\hline Joint diseases & $\begin{array}{l}2978 \\
(60.9)\end{array}$ & $1938(59.5)$ & $1040(63.8)$ \\
\hline Dementia & $\begin{array}{l}2111 \\
(43.2)\end{array}$ & $1421(43.6)$ & $690(42.4)$ \\
\hline Parkinson's disease & $335(6.9)$ & $233(7.2)$ & $102(6.3)$ \\
\hline Diabetes & $\begin{array}{l}1615 \\
(33.0)\end{array}$ & $1081(33.2)$ & $534(32.8)$ \\
\hline Vision or Hearing impairment & $342(7.0)$ & $221(6.8)$ & $121(7.4)$ \\
\hline Fractures & $892(18.3)$ & $580(17.8)$ & $312(19.2)$ \\
\hline Cancer & $\begin{array}{l}1404 \\
(28.7)\end{array}$ & $939(28.8)$ & $465(28.6)$ \\
\hline $\begin{array}{l}\text { Month of receiving regular home visits: median } \\
\text { (IQR) }\end{array}$ & $7(2-12)$ & $7(2-12)$ & $7(2-12)$ \\
\hline The frequent use of emergency home visits* & $634(13.0)$ & $424(13.0)$ & $210(12.9)$ \\
\hline \multicolumn{4}{|c|}{ Abbreviations: SD = Standard Deviation, IQR = Inter Quartile Range. } \\
\hline
\end{tabular}

The mean age was 84.1 (standard deviation 7.4) years for the entire sample, and $40.3 \%$ of participants were male. There were no clear differences in patient characteristics between the two cohorts. In the first year after the start of the regular home visit or by the month after the end of the regular home visit, $13.0 \%$ $(424 / 3,259)$ and $12.9 \%(210 / 1,629)$ of the derivation cohort and the validation cohort, respectively, used emergency house calls once a month or more on average. The distributions of the average number of emergency house calls per month are shown in Supplementary Appendix 2. The derivation and validation cohorts showed right-skewed distributions, with 0 accounting for approximately $50 \%$. 
The characteristics associated with the frequent use of emergency house calls in the univariable analysis (chi-squared tests or Fisher's exact test) and multivariable analysis are shown in Table 2. 
Table 2

Univariate and multivariable analysis in the derivation cohort.

\section{Univariable analysis}

$\begin{array}{|llllll|}\begin{array}{l}\text { Non- } \\ \text { frequent } \\ \text { use of } \\ \text { emergency } \\ \text { house } \\ \begin{array}{l}\text { calls } \\ (\mathrm{n}=2,835)\end{array}\end{array} & \begin{array}{l}\text { Frequent } \\ \text { use of } \\ \text { emergency } \\ \text { house } \\ \text { calls* } \\ (\mathrm{n}=424)\end{array} & \begin{array}{l}\mathrm{P} \\ \text { value }\end{array} & \begin{array}{l}\text { OR } \\ (95 \% \mathrm{Cl})\end{array} & \begin{array}{l}\mathrm{P} \\ \text { value }\end{array} & \begin{array}{l}\beta \\ \text { coefficient }\end{array} \\ \mathrm{n}(\%) & \mathrm{n}(\%) & & & \\ \end{array}$

Multivariable logistic regression

OR

(95\% Cl)

\section{Lasso Point logistic regression score}

\section{Age category} (years)

\begin{tabular}{|c|c|c|c|c|c|c|c|}
\hline $65-74$ & 289 (10.2) & $64(15.1)$ & 0.002 & Reference & - & - & - \\
\hline $75-84$ & $\begin{array}{l}1090 \\
(38.5)\end{array}$ & $170(40.1)$ & & $\begin{array}{l}0.88 \\
(0.63- \\
1.25)\end{array}$ & 0.483 & - & - \\
\hline $85-94$ & $\begin{array}{l}1249 \\
(44.1)\end{array}$ & $153(36.1)$ & & $\begin{array}{l}0.85 \\
(0.60- \\
1.22)\end{array}$ & 0.390 & - & - \\
\hline$\geq 95$ & $207(7.3)$ & $37(8.7)$ & & $\begin{array}{l}1.41 \\
(0.86- \\
2.30)\end{array}$ & 0.169 & - & - \\
\hline $\begin{array}{l}\text { Gender: male } \\
\text { (vs. female) }\end{array}$ & $\begin{array}{l}1107 \\
(39.1)\end{array}$ & $210(49.5)$ & $\begin{array}{l}<.001 \\
0.001\end{array}$ & $\begin{array}{l}1.23 \\
(0.98- \\
1.54)\end{array}$ & 0.079 & - & - \\
\hline $\begin{array}{l}\text { Medical } \\
\text { procedure at } \\
\text { home }\end{array}$ & & & & & & - & - \\
\hline Self-injection & $67(2.4)$ & $6(1.4)$ & 0.218 & $\begin{array}{l}0.64 \\
(0.27- \\
1.54)\end{array}$ & 0.322 & - & - \\
\hline $\begin{array}{l}\text { Central venous } \\
\text { nutrition }\end{array}$ & $31(1.1)$ & $14(3.3)$ & $<0.001$ & $\begin{array}{l}1.66 \\
(0.84- \\
3.26)\end{array}$ & 0.141 & - & - \\
\hline Enteral nutrition & $9(0.3)$ & $3(0.7)$ & 0.198 & $\begin{array}{l}1.48 \\
(0.38- \\
5.79)\end{array}$ & 0.572 & - & - \\
\hline
\end{tabular}

Abbreviations: $\mathrm{OR}=$ odds ratio, $\mathrm{Cl}=$ confidence interval.

* Emergency house calls once per month or more on average during each observation period. 


\begin{tabular}{|c|c|c|c|c|c|c|c|}
\hline & \multicolumn{3}{|c|}{ Univariable analysis } & \multicolumn{2}{|c|}{$\begin{array}{l}\text { Multivariable } \\
\text { logistic regression }\end{array}$} & \multirow{2}{*}{ 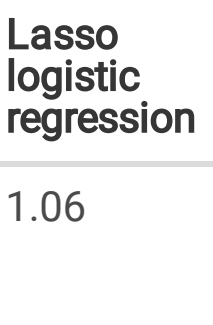 } & \multirow{2}{*}{$\begin{array}{l}\text { Point } \\
\text { score }\end{array}$} \\
\hline $\begin{array}{l}\text { Home oxygen } \\
\text { therapy }\end{array}$ & $133(4.7)$ & $66(15.6)$ & $<0.001$ & $\begin{array}{l}2.55 \\
(1.80- \\
3.62)\end{array}$ & $<0.001$ & & \\
\hline $\begin{array}{l}\text { Use of } \\
\text { ventilator/ } \\
\text { tracheostomy } \\
\text { performed }\end{array}$ & $23(0.8)$ & $1(0.2)$ & 0.161 & $\begin{array}{l}0.18 \\
(0.02- \\
1.36)\end{array}$ & 0.096 & - & - \\
\hline $\begin{array}{l}\text { Urinary self- } \\
\text { catheterization }\end{array}$ & $10(0.4)$ & $3(0.7)$ & 0.234 & $\begin{array}{l}2.66 \\
(0.68- \\
10.37)\end{array}$ & 0.158 & - & - \\
\hline $\begin{array}{l}\text { Long-term care } \\
\text { need levels }\end{array}$ & & & & & & - & - \\
\hline $\begin{array}{l}\text { Care need levels } \\
4-5 \text { (vs. } 1-3)\end{array}$ & $\begin{array}{l}1033 \\
(36.4)\end{array}$ & 219 (51.7) & $<0.001$ & $\begin{array}{l}1.84 \\
(1.48- \\
2.29)\end{array}$ & $<0.001$ & 0.64 & 3 \\
\hline \multicolumn{8}{|l|}{$\begin{array}{l}\text { Medical } \\
\text { diagnosis at the } \\
\text { start of the } \\
\text { regular home } \\
\text { visit }\end{array}$} \\
\hline $\begin{array}{l}\text { Cerebrovascular } \\
\text { diseases }\end{array}$ & $\begin{array}{l}1142 \\
(40.3)\end{array}$ & 135 (31.8) & 0.001 & $\begin{array}{l}0.78 \\
(0.62- \\
0.98)\end{array}$ & 0.037 & - & - \\
\hline Cardiac disease & $\begin{array}{l}1623 \\
(57.3)\end{array}$ & $240(56.6)$ & 0.802 & $\begin{array}{l}0.92 \\
(0.73- \\
1.16)\end{array}$ & 0.467 & - & - \\
\hline $\begin{array}{l}\text { Lower } \\
\text { respiratory tract } \\
\text { disease }\end{array}$ & $\begin{array}{l}1237 \\
(43.6)\end{array}$ & $241(56.8)$ & $<0.001$ & $\begin{array}{l}1.29 \\
(1.03- \\
1.62)\end{array}$ & 0.027 & - & - \\
\hline Joint diseases & $\begin{array}{l}1679 \\
(59.2)\end{array}$ & $259(61.1)$ & 0.467 & $\begin{array}{l}0.91 \\
(0.73- \\
1.15)\end{array}$ & 0.440 & - & - \\
\hline Dementia & $\begin{array}{l}1281 \\
(45.2)\end{array}$ & $140(33.0)$ & $<0.001$ & $\begin{array}{l}0.92 \\
(0.72- \\
1.16)\end{array}$ & 0.474 & - & - \\
\hline $\begin{array}{l}\text { Parkinson's } \\
\text { disease }\end{array}$ & 207 (7.3) & $26(6.1)$ & 0.383 & $\begin{array}{l}1.10 \\
(0.70- \\
1.72)\end{array}$ & 0.676 & - & - \\
\hline
\end{tabular}

Abbreviations: $\mathrm{OR}=$ odds ratio, $\mathrm{Cl}=$ confidence interval.

* Emergency house calls once per month or more on average during each observation period. 


\begin{tabular}{|c|c|c|c|c|c|c|c|}
\hline & \multicolumn{3}{|c|}{ Univariable analysis } & \multicolumn{2}{|c|}{$\begin{array}{l}\text { Multivariable } \\
\text { logistic regression }\end{array}$} & \multirow{2}{*}{$\begin{array}{l}\text { Lasso } \\
\text { logistic } \\
\text { regression }\end{array}$} & \multirow{2}{*}{$\begin{array}{l}\text { Point } \\
\text { score }\end{array}$} \\
\hline Diabetes & $928(32.7)$ & $153(36.1)$ & 0.172 & $\begin{array}{l}1.08 \\
(0.85- \\
1.36)\end{array}$ & 0.525 & & \\
\hline $\begin{array}{l}\text { Vision or } \\
\text { Hearing } \\
\text { impairment }\end{array}$ & $203(7.2)$ & $18(4.3)$ & 0.026 & $\begin{array}{l}0.58 \\
(0.35- \\
0.96)\end{array}$ & 0.035 & - & - \\
\hline Fractures & $514(18.1)$ & $66(15.6)$ & 0.198 & $\begin{array}{l}1.01 \\
(0.75- \\
1.36)\end{array}$ & 0.940 & - & - \\
\hline Cancer & $707(24.9)$ & $232(54.7)$ & $\begin{array}{l}< \\
0.001\end{array}$ & $\begin{array}{l}3.10 \\
(2.46- \\
3.91)\end{array}$ & $<0.001$ & 1.21 & 5 \\
\hline \multicolumn{8}{|c|}{ Abbreviations: $\mathrm{OR}=$ odds ratio, $\mathrm{Cl}$ = confidence interval. } \\
\hline * Emergency & calls once & month or $\mathrm{n}$ & & e durir & & n period. & \\
\hline
\end{tabular}

In the univariable analysis, patient in the group that made frequent use of emergency house calls tended to be 65-84 and $\geq 95$ years, male, more likely to be receiving central venous nutrition, home oxygen therapy, and had a higher care need level. Regarding patients' diseases, lower respiratory diseases and cancer were more frequent in the group that frequently used emergency house calls, whereas cerebrovascular diseases, dementia, and visual or hearing impairment were less frequent. In multivariable logistic regression analysis, home oxygen therapy, care need level 4-5 (compared with care need level 13 ), lower respiratory disease, and cancer showed positive associations with the frequent use of emergency house calls, whereas vision and hearing impairment showed negative associations.

Of the 19 pre-specified predictors included in the Lasso logistic model, three were found to be significant predictors of the frequent use of emergency house calls: home oxygen therapy, care need level 4-5, and cancer. The result of the beta coefficient and the created score is summarized in Table 2. The distribution of the total score in the derivation cohort and the validation cohort is shown in Supplementary Appendix 3. The ROC curve and the AUC for the risk score are shown in Figure 2. Compared with the model with all variables pre-specified (AUC; 0.729), the predictive ability of the 3-factor risk score (AUC; 0.708 ) was only slightly lower.

The AUC in the validation cohort was 0.708 , indicating a moderate discriminatory ability. The calculation of the score and the estimated probability of frequent use of emergency house calls are shown in Figure 3. Figure 4 shows the calibration of the prediction model. The plotted points are relatively close to the $45^{\circ}$ line, demonstrating good calibration over the whole range of the predictions.

\section{Discussion}


Using claims data from two Japanese cities, we developed and internally validated a multivariable risk prediction model and scoring system to predict the frequent use of emergency house calls. This risk score showed modest discrimination, good calibration, and satisfactory internal validity. It provides a useful and easily applicable tool for identifying high-risk patients who may require frequent emergency house calls in the community. The home health care team should promote understanding of the patient's disease and prepare for anticipated events for these patients and their families.

Our findings regarding the association between cancer patients and the frequent use of emergency house calls are consistent with a previous study reporting that cancer patients are almost seven times more likely to become frequent attenders at primary care after-hours services compared with non-cancer patients [19]. According to a previous study, cancer in the digestive or respiratory system was the most frequent reason for cancer patients' use of primary care after-hours services [20]. Another previous study showed that the most common complaints in patients with advanced cancer in the emergency department were pain, shortness of breath, and vomiting, which could also be the reason for emergency house calls [21]. In addition, as "death" is one of the major reasons for emergency house calls in Japan $[7,8]$, calls due to end-of-life care may be included in cancer patients.

We found that the frequent use of emergency house calls was more likely to occur in patients with highcare need levels. This finding may be explained as follows: Higher level of care needed is associated with fever events, and fever is a significant reason for emergency house calls [7]. A previous study in Japan found that fever was more likely in patients with care need levels $\geq 3$ than $\leq 2$, and the conditions most likely to cause fever were pneumonia/bronchitis, skin and soft tissue infections, and urinary tract infections [22]. The authors explained that this was due to an increased risk of aspiration because of decreased strength to cough and increased susceptibility to infections caused by decreased muscle strength and poor nutritional status.

Home oxygen use was associated with the frequent use of emergency house calls. This is consistent with a study in Japan in which dyspnea was a common chief complaint and there was an association between emergency house calls for dyspnea and home oxygen use [7]. Another study has shown that chronic obstructive pulmonary disease (COPD) is more prevalent among those requiring frequent primary care after-hours services and that complications and exacerbations of chronic diseases are the reasons for this help-seeking behavior [19].

This risk score would be useful to allocate medical resources and maintain a home healthcare system in the community. In Japan, a revision of the medical fee schedule introduced HCSCs with home care support functions available 24-hour a day until the patient dies, which enabled 24-hour home visit care at the patient's request in 2006 [23]. In 2012, enhanced HCSCs, which required the appointment of three or more full-time doctors, were institutionalized. Although the number of HCSCs facilities is increasing, enhanced HCSC accounts for only a small percentage of the total HCSC (approximately 24\% in 2018) [6]. Moreover, many general clinics do not meet HCSC requirements while providing home visits [6]. Most of these clinics are in solo practice and have difficulties providing three or more full-time doctors [24]. 
Therefore, our tool would be helpful to identify high-risk patients who may require the frequent use of emergency house calls and reduce the burden on primary care physicians, especially for solo practitioners, by associating high-risk patients to well-staffed medical institutions, such as enhanced HCSCs.

Our tool is based on information readily available in a primary care setting. Therefore, this score can indicate the risk at the start of the regular home visits to allow targeting a timely approach for high-risk patients. Furthermore, because this score contains only three factors, it is easy to remember and can be quickly calculated in clinical practice.

To the best of our knowledge, this is the first study to develop a risk prediction model for the frequent use of emergency house calls among older people who receive regular home visits. However, this study has several limitations. First, we did not externally validate the proposed model; further validation in different populations is warranted. Second, we did not examine some potential predictors that are known riskfactors, such as the urethral catheter placement [7], because information on these factors was not available. Third, some clinical information generally obtained in clinical settings (such as symptoms, laboratory data, and imaging findings) was unavailable in the database. Fourth, although the instances in which patients and their families perceive the need to request emergency house calls may be influenced by appropriate symptom management, enhanced home health care, palliative care with team coordination, and family caregiver education and support, we were unable to consider these factors. These factors should be included to improve risk score performance in future studies.

\section{Conclusions}

This easy-to-use risk scoring allows physicians to prospectively identify patients at high risk for emergency house calls and would help in reducing the physical and psychological burden on primary care physicians by taking measures such as clustering high-risk patients in well-equipped medical facilities, ultimately helping to preserve home health care in the community.

\section{Declarations}

\section{Ethics approval and consent to participate}

This study was approved by the Ethics Committee of the University of Tsukuba (approval numbers: 14456 and 1666).

\section{Consent for publication}

Consent of individual participants was waived because of the anonymous nature of the data. 


\section{Availability of data and materials}

The datasets supporting the conclusions of this article are available from the corresponding author on reasonable request.

\section{Competing interests}

The authors have no conflicts of interest.

\section{Funding}

This research was supported by a grant-in-aid from the Ministry of Health, Labour and Welfare; Health, Labour and Welfare Sciences Research Grant, Japan; Research on Region Medical (21IA1010).

\section{Authors' contributions}

Study concept and design: Yu Sun, Masao Iwagami, Miho Ishimaru, Kazuaki Uda. Acquisition of data: Naoaki Kuroda, Satoru Yoshie, Tatsuro Ishizaki, Katsuya lijima. Maintenance of data: Jun Komiyama, Miho Ishimaru. Statistical analysis and interpretation of data: Yu Sun, Masao Iwagami, Kazuaki Uda. Preparation of manuscript: all authors contributed to the drafting and critical revision of the manuscript. All authors have approved the final manuscript.

\section{Acknowledgments}

We would like to thank Editage (www.editage.jp) for its English language editing.

\section{References}

1. Leibowitz R, Day S, Dunt D. A systematic review of the effect of different models of after-hours primary medical care services on clinical outcome, medical workload, and patient and GP satisfaction. Fam Pract. 2003;20:311-7.

2. T Huibers L, Giesen P, Wensing M, Grol R. Out-of-hours care in western countries: assessment of different organizational models. BMC Health Serv Res. 2009;9:105.

3. van Uden CJ, Giesen PH, Metsemakers JF, Grol RP. Development of out-of-hours primary care by general practitioners (GPs) in the Netherlands: from small-call rotations to large-scale GP cooperatives. Fam Med. 2006;38:565-9.

4. Japan Cabinet Office. Annual report on the aging society. 2019. https://www8.cao.go.jp/kourei/english/annualreport/2019/pdf/2019.pdf. Accessed 15 Nov 2021. 
5. Ministry of Health, Labour and Welfare. Promotion of Long-Term Care and Home Care (in Japanese). 2011. http://www.mhlw.go.jp/stf/seisakunitsuite/bunya/0000061944.html. Accessed 15 Nov 2021.

6. General Meeting Materials of Central Social Insurance Medical Council (in Japanese). 2019. https://www.mhlw.go.jp/content/12404000/000563523.pdf. Accessed 15 Nov 2021.

7. Kuroda K, Miura T, Kuroiwa S, Kuroda M, Kobayashi N, Kita K. What are the factors that cause emergency home visit in home medical care in Japan? J Gen Fam Med. 2021;22:81-6.

8. Kaneko M, Van Boven K, Takayanagi H, Kusaba T, Yamada T, Matsushima M. Multicentre descriptive cross-sectional study of Japanese home visit patients: reasons for encounter, health problems and multimorbidity. Fam Pract. 2020;37:227-33.

9. Ikegami N, Yoo BK, Hashimoto H, Matsumoto M, Ogata H, Babazono A, et al. Japanese universal health coverage: evolution, achievements, and challenges. Lancet. 2011;378:1106-15.

10. ICD-10 Corresponding Diagnosis Code Master (in Japanese).

http://www2.medis.or.jp/stdcd/byomei/index.html. Accessed 15 Nov 2021.

11. Matsuda T, Iwagami M, Suzuki T, Jin X, Watanabe T, Tamiya N. Correlation between the Barthel index and care need levels in the Japanese long-term care insurance system. Geriatr Gerontol Int. 2019;19:1186-7.

12. Tsutsui T, Muramatsu N. Care-needs certification in the long-term care insurance system of Japan. J Am Geriatr Soc. 2005;53:522-7.

13. Reference materials for the 1st National Conference on home medical care (in Japanese). 2016. https://www.mhlw.go.jp/file/05-Shingikai-10801000-Iseikyoku-Soumuka/0000129546.pdf. Accessed 15 Nov 2021.

14. Iwagami M, Taniguchi Y, Jin X, Adomi M, Mori T, Hamada S, et al. Association between recorded medical diagnoses and incidence of long-term care needs certification: a case control study using linked medical and long-term care data in two Japanese cities. Annals Clin Epidemiol. 2019;1:56-68.

15. Tibshirani R. Regression shrinkage and selection via the Lasso. J R Stat Soc B. 1996;58:267-88.

16. Oh E, Yoo TK, Park EC. Diabetic retinopathy risk prediction for fundus examination using sparse learning: a cross-sectional study. BMC Med Inform Decis Mak. 2013;13:106.

17. Sabourin JA, Valdar W, Nobel AB. A permutation approach for selecting the penalty parameter in penalized model selection. Biometrics. 2015;71:1185-94.

18. Moons KG, Harrell FE, Steyerberg EW. Should scoring rules be based on odds ratios or regression coefficients? J Clin Epidemiol. 2002;55:1054-5.

19. Sandvik H, Hunskaar S. Frequent attenders at primary care out-of-hours services: a registry-based observational study in Norway. BMC Health Serv Res. 2018;18:492.

20. Thoresen CK, Sandvik H, Hunskaar S. Cancer patients' use of primary care out-of-hours services: a cross-sectional study in Norway. Scand J Prim Health Care. 2016;34:232-9.

21. Alsirafy SA, Raheem AA, Al-Zahrani AS, Mohammed AA, Sherisher MA, El-Kashif AT, et al. Emergency department visits at the end of life of patients With terminal cancer: pattern, causes, and avoidability. 
Am J Hosp Palliat Care. 2016;33:658-62.

22. Yokobayashi K, Matsushima M, Watanabe T, Fujinuma Y, Tazuma S. Prospective cohort study of fever incidence and risk in elderly persons living at home. BMJ Open. 2014;4:e004998.

23. Ohta H. Current conditions and issues for home care support clinics. Jpn Med Assoc J. 2015;58:6-9.

24. General Meeting Materials of Central Social Insurance Medical Council (in Japanese). 2013. https://www.mhlw.go.jp/file/05-Shingikai-12404000-Hokenkyoku-Iryouka/0000027959.pdf. Accessed 15 Nov 2021.

\section{Figures}

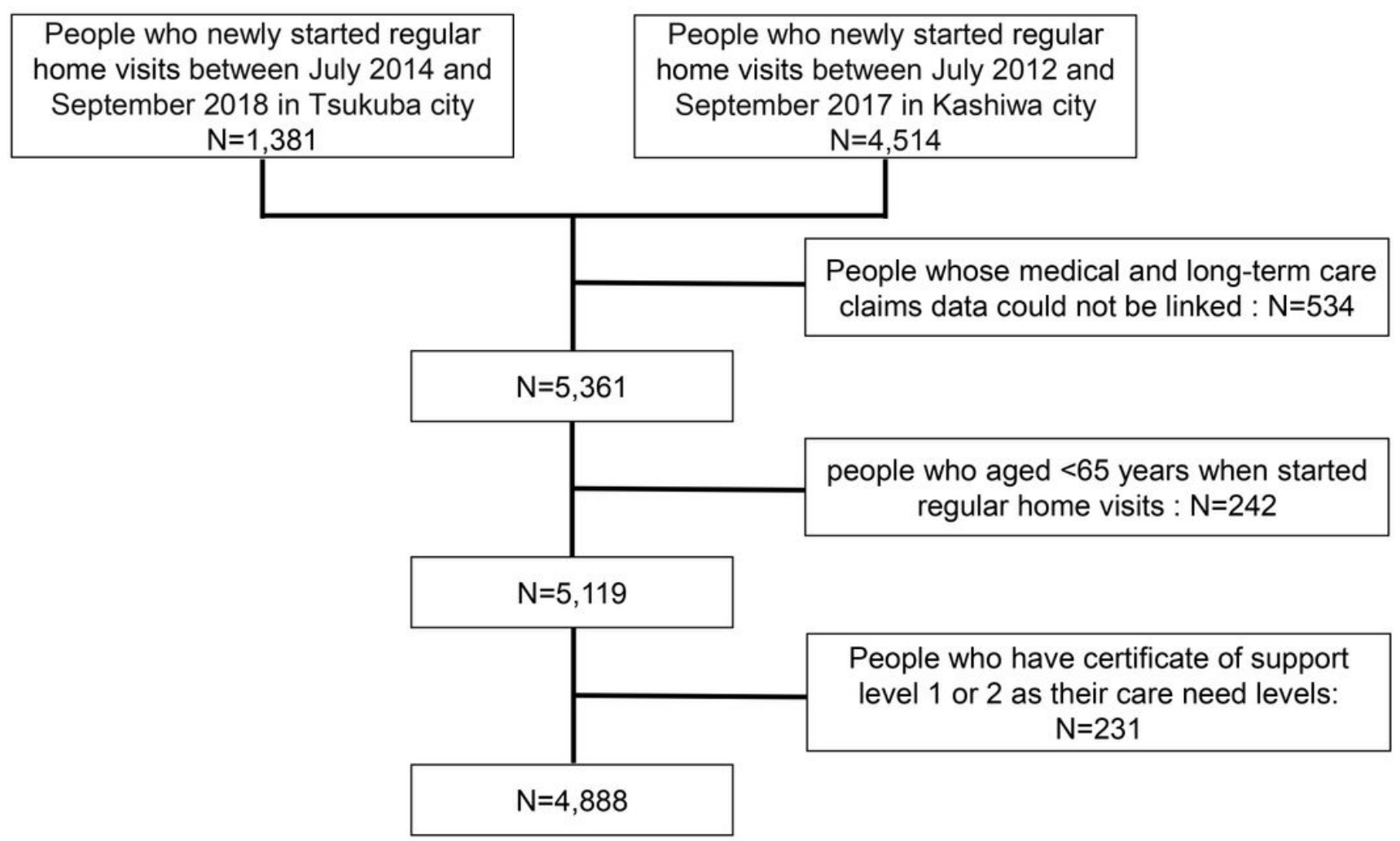

Figure 1

$<p>$ Flow chart of study participant selection. $</ p>$ 


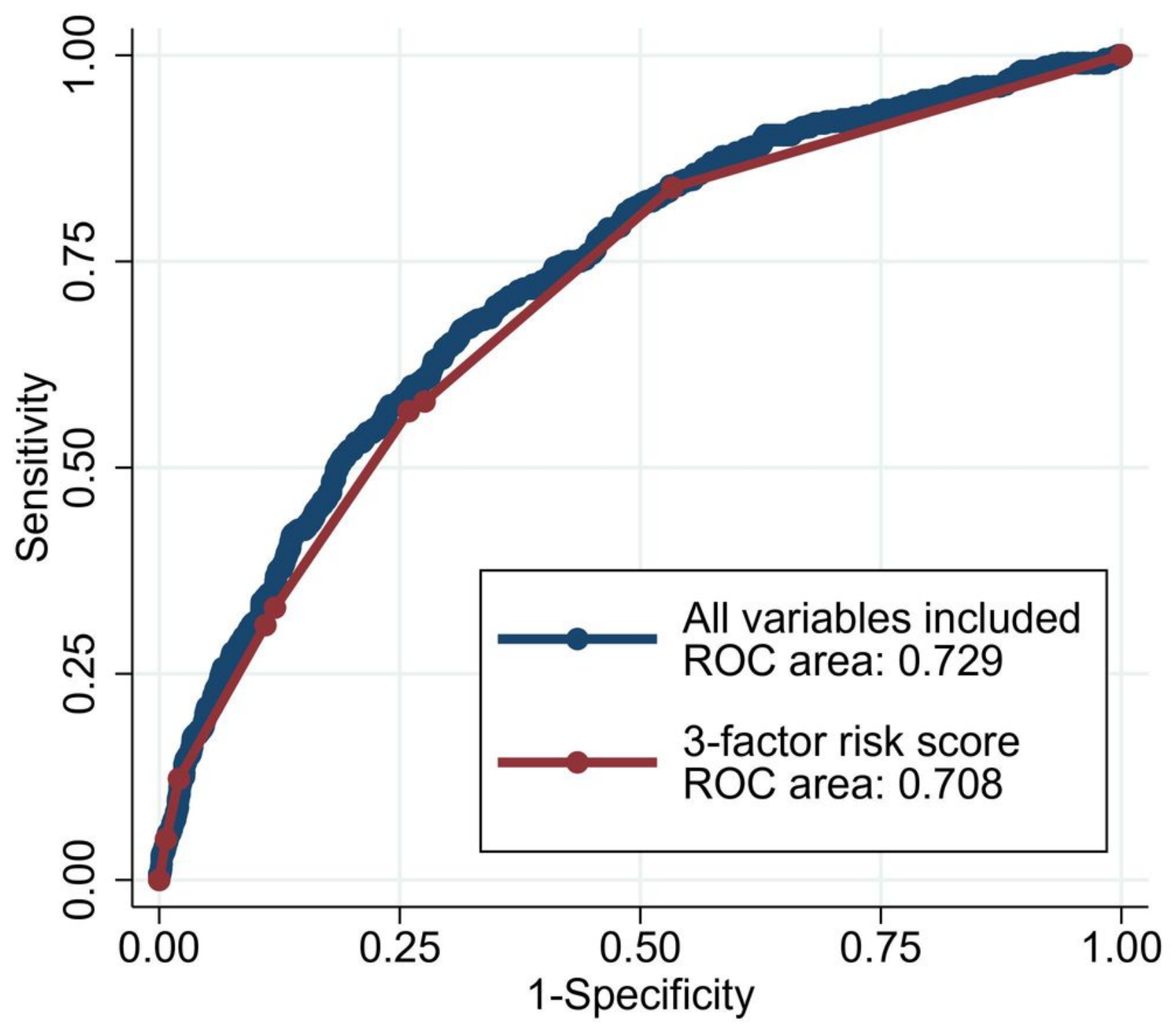

Figure 2

$<p>$ Receiver operating characteristic (ROC) curves and area under the curve (AUC) for the risk score in the derivation cohorts.\&nbsp; $</ p>$ 
Calculation of the risk score

\begin{tabular}{ll}
\hline Home oxygen therapy & 3 \\
Care need level & \\
$1-3$ & 0 \\
$4-5$ & 4 \\
Cancer & 5 \\
\hline
\end{tabular}

\section{Estimated risk of the frequent use of emergency house calls}

\begin{tabular}{cc}
\hline Total score & Estimated risk (\%) \\
\hline 0 & 5.9 \\
3 & 11.3 \\
4 & 14.0 \\
5 & 17.2 \\
7 & 25.1 \\
8 & 29.9 \\
9 & 35.2 \\
12 & 52.7 \\
\hline
\end{tabular}

Figure 3

$<p>$ Calculation of scores and the corresponding estimated probabilities of the frequent use of emergency house calls. $</ p>$ 


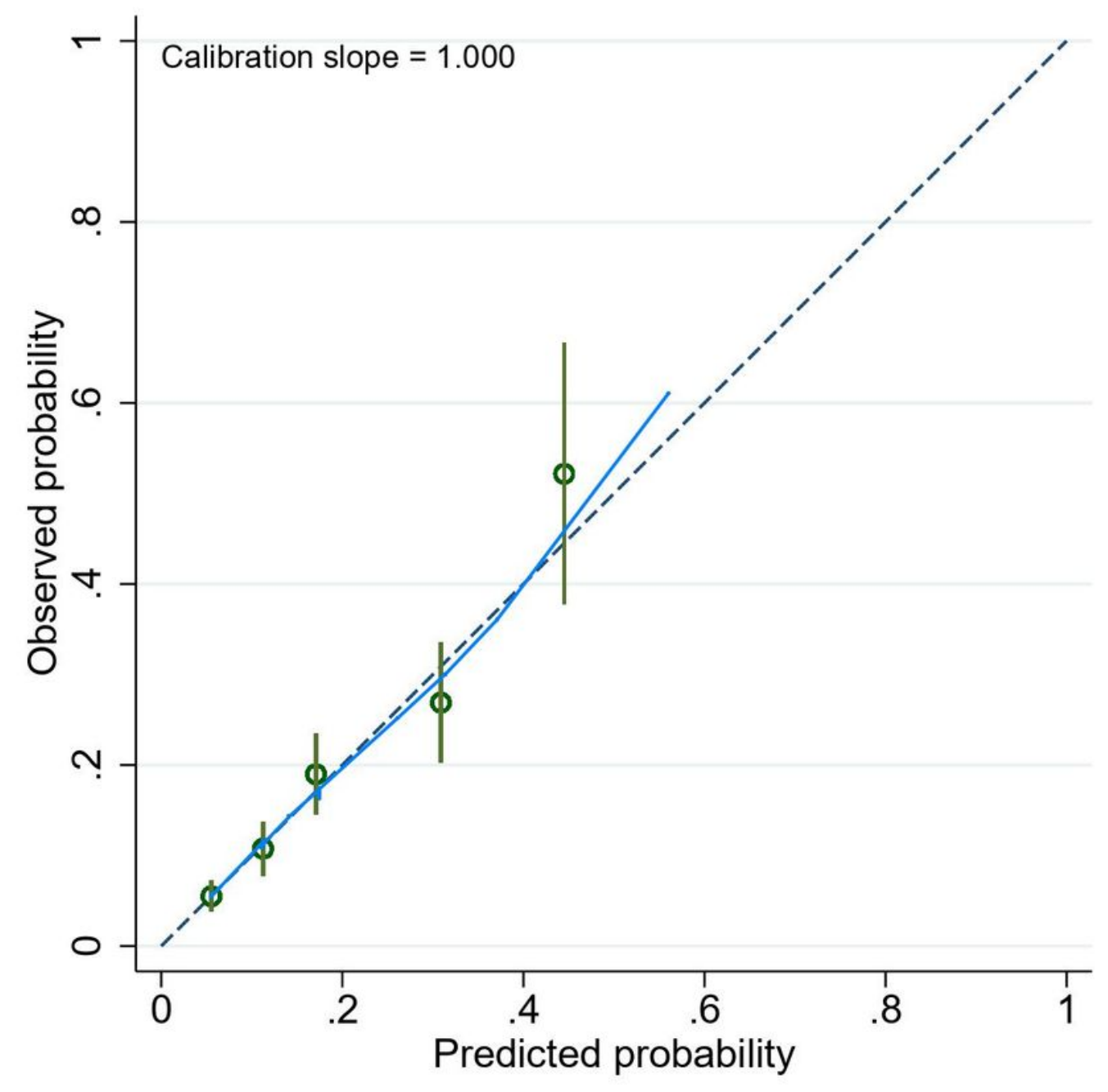

Figure 4

$<p>$ Calibration plot for predicting the frequent use of emergency house calls. The solid curve is the Loessestimated calibration curve. $</ p>$

\section{Supplementary Files}

This is a list of supplementary files associated with this preprint. Click to download.

- SupplementaryAppendix1ver6.docx

- SupprementaryAppendix2ver7.pdf

- SupprementaryAppendix3ver7.pptx 